\title{
New Understanding of the Barriers to Foreign Students Adaptation in the Changing Educational Landscape: A Narrative Analysis
}

\author{
Elena Tikhonova ${ }^{1,2}$, Marina Kosycheva ${ }^{3}$, Galina Efremova ${ }^{4}$ \\ ${ }^{1}$ MGIMO University \\ ${ }^{2}$ Peoples' Friendship University of Russia (RUDN University) \\ ${ }^{3}$ Moscow State University of Food Production \\ ${ }^{4}$ Russian Academy of Education
}

\begin{abstract}
Correspondence concerning this article should be addressed to Marina Kosycheva, Department of Linguistics and Professional Communication, Moscow State University of Food Production, 11 Volokolamskoe Shosse, Moscow, Russian Federation, 125080.E-mail: kosychevama@mgupp.ru
\end{abstract}

\begin{abstract}
The COVID-19 pandemic has changed nowadays life in every aspect so irreversibly that there is no doubt that the educational landscape must be continuously re-evaluated and revised. In this regard, particular emphasis is given to the issues of academic mobility and adaptation of foreign students. The aim of the study is to clarify a new understanding of the issues traditionally faced by foreign students in universities in the host country and to analyze new barriers that have arisen as a result of the spread of the COVID-19 pandemic. This paper reports on a narrative research study exploring the experiences and perceptions of 42 first-year bachelor and master foreign students having come to Russia for the first time. Taking into account that human behaiviour can be predicted through language patterns, we analysed language features to compare the participants' rational and emotional perception of the barriers to adaptation highlighted from their narratives. The findings suggest that almost all issues traditionally faced by foreign students have received a new understanding or have changed their hierarchy in their perception. Contemporary challenges have also created new barriers to adaptation. Temporalities and restrictions in physical movement received special emphasis as an obstacle to adaptation of foreign students. In the context of the total transformation that awaits higher education after the end of the pandemic and its transition to a hybrid format, the results of this study can be used by academic developers to establish a system of foreign students' psychological adaptation.
\end{abstract}

Keywords: narratives, foreign students, barriers to adaptation, temporalities, restrictions in physical movement, evaluative language analysis

\section{Introduction}

The COVID-19 pandemic has affected the educational landscape around the world in a fundamental way. It could not but determine the modification of the barriers faced by foreign students in the context of the export of education. Researchers around the world are engaged in elaborating models of psychological adaptation of foreign students to the realities of educational institutions of the host society, and also they study foreign students' adaptation effectiveness and how it is related to their academic achievement and earning a degree (Moussa, 2021), their balancing through social experience (Selvitopu, 2020). Scholars focus on developing models of intercultural competence, its main components being intercultural stability and interest, the lack of ethnocentrism and intercultural interaction management (Gritsenko et al., 2021), highlight the barriers and enablers for the adaptation and integration of international students, that turns to be differences in teaching and learning philosophies, the dominant culture's fear of the "others" or cultural insecurity (Abdulai et al., 2021).

Although these studies were carried out by authors from all over the world, they describe fairly similar barriers that foreign students face upon arrival in the country regardless of the context of a particular country. Foreign 
students face a great deal of challenges when they enter a new cultural environment. Among these barriers the most mentioned are discrimination and stereotypes (Bello, 2021; Green \& Mayatt, 2011), pressure to assimilate culturally and acculturation challenges (Balante et al., 2021; Karim et al., 2021), native-born hostility towards immigrant students (Murillo, 2021). Such psychological problems as depression (Kamalova et al., 2021), high level of stress (Chaiyasat, 2020), loss of self-efficacy (Céspedes et al., 2021) and self-stigmatization (Harvey, 2001; Glace et al., 2021) are also associated with the barriers to successful adaptation. Foreign students mention facing problems with job seeking and problems related to integration and adaptation to the new context of life (Gonta \& Bulgac, 2019; Baker et al., 2021), also they noted as a barrier for their future career planning absence of specific campus programming aimed at helping foreign students make the transition from academic life to employment (Tikhonova et al., 2021). But still, one of the most vital challenges is a language barrier (Stevens, 2012; Green \& Mayatt, 2011; Podboj \& Lujić, 2020).

Meanwhile, some papers describing the barriers of the "new generation" have appeared so far, and if before the pandemic some of them were perceived as unobvious or picking up steam, the pandemic situation not only actualized them, but turned them into the most significant and decisive ones. Let's consider temporalities, for example. Even before entering the country most of the migrant students experienced a long and exhausting period of time waiting for their departure due to the unpredictable process of visa application. When in the host country, their whole life also becomes dependent on the legal framework of visa and residence permit regulations and the need to renew them. Migrant students experience temporal effects of the border and visa regime on their everyday lives focusing on the control over and through time (Tazzioli, 2018). 'Waiting' is increasingly recognized as an undeniable aspect of the migration experience (Baas, 2019). Moreover, onlinefocused delivery of education affected almost $90 \%$ of higher education institutions around the world (AlemanyArrebola et al., 2020) and turned out to be a new challenge for bothforeign students and students from the host society resulting in low levels of academic self-efficacy. Due to the closed borders foreign students face increased challenges that generate their anxieties about their future career (Hari et al., 2021). But the greatest concern today is restrictions in physical student mobility and shutdown, they are considered to be the biggest challenges that occurred in higher education during the COVID-19 (Yıldırım, 2021).

Hence, it is obvious that the COVID-19 pandemic has caused not only a transformation in the perception of barriers foreign students face in the universities in the context of the export of education, but also has actualized new barriers that are transforming the educational landscape. The aim of this study is to clarify a new understanding of the barriers traditionally faced by foreign students and to analyze those of the "new generation".

\section{Methodology}

\section{Theoretical Background}

An important aspect of any research is the selection of a method for obtaining and processing qualitative data, which makes it possible to efficiently identify and describe the phenomenon under study. Analysis of studies devoted to the problems of localization of aspects that complicate the foreign students' adaptation let us state narratives as the desired method. Thus, Webster and Mertova (2007, p. 1) assert that 'narrative records human experience through the construction and reconstruction of personal stories'.

The notion of narrative was observed from varied perspectives of different social and linguistic traditions, and as a result is difficult to define. Narratives being discursive constructions also convey social analysis denoting how social phenomena reflect in them. Sociolinguistic analysis of personal narratives implies not only focusing on the structure and syntactic features of canonical narratives (Labov, 1972) but also treats them as a type of social interaction (Norton, 2013; Podboj \& Lujić, 2020). In this light narrative discourse is understood as specific communicative events designating linguistic practices and complex social and ideological processes behind them (Podboj \& Lujić, 2020).

Consoli (2021) insists that narrative inquiry is not only just telling stories, but systematical analysis of "the underlying insights and assumptions that the story illustrates" (Bell, 2002, p. 208) aimed at the understanding, creation and sharing of new knowledge. Moreover, the main feature of narrative discourse is to represent the 
viewpoints (van Krieken, 2018). The former can be distinguished with the help of linguistic markers that can be represented in discourse in various ways.

J.C. Gimenez (2010) distinguishes two main approaches to analyze narratives: componential and functional. The componential analysis consists of identifying and examining the elements of a narrative and their interaction. Functional analysis, on the contrary, studies the purpose of narratives. Among the most functions that narrative can serve, the scholars widely studiedhow narrators represent or interpret the world (van Krieken, 2018); how they represent self and others (Kowalska, 2021); and how they construct their - gendered, ethnic or class identities (Bamberg, 2012).

Functional analysis is helpful to represent how the migrant students tell the stories of their adaptation period in the host society and what challenges they face due to the pandemic and to show how a narrative approach can generate new knowledge by revealing the attitudes of the host society to foreign students and their perception of the host society.

A lot of research is done on sustaining a sense of self within a new cultural environment. There are some terms associated with displeasing development of new identities in cross-cultural experiences, among them 'liminality', 'third spaces', 'in-betweeners' (Grimshaw \& Sears, 2008; Boland, 2020).

The narrative presentation of the cultural experience of behavior in typical social situations is the most frequent form of substantiating certain behavioral norms and endows a person's actions with a stable meaning. The narrative makes it possible to highlight national images and mentality, ethnocultural models of behavior (Aleschanova, 2006). Narratives can help to understand complex systems and allow us to connect time and disconnected elements into a whole system to find the meaning (Tomassini et al., 2021). Individuals and groups construct narratives in order to organise their experiences and 'map their reality' (Wilkins \& Thompson, 1991).

Narrativeslet us learn something in a new way. They serve as a distinct form of discourse that focuses on the biographical, social, cultural and historical situations that have conditioned life experiences (Denzin \& Lincoln, 2005). Narrative enquiry analyzes life experiences as narrated by those who live them, create coherence and meaning, reflect their understanding of events and behaviours over time (Tomassini et al., 2021; Denzin \& Lincoln, 2005). This technique is also supported by research on the cross-cultural experiences of international students where it is seen as a particularly appropriate way to explore the process of reforming professional and cultural identities in a new environment (Green, 2011; Belford, 2017). In the linguistic approach to narrative, text can be expounded according to its various levels of structure and meaning (Gee, 1991; Riessman,1993; Tomassini, 2021), illustrate its value and interpret it.

\section{Participants}

42 migrant students aged from 17 to 37 (mean age =20.8, 21 male, 21 female) took part in the study. The older participants seeking for a Master degree were included in the study because of the added value of their perspectives. The students came from Uzbekistan (5), Afghanistan (4), Kazakhstan (3), Nigeria (3), Albania (2), Turkmenistan (2), Azerbaijan (2), Egypt (2), Syria (2),Tajikistan (2), Moldova (1), Republic of Belarus (1), China (1), Indonesia (1), Brazi (1), Macedonia (1), Uganda (1), Serbia (1), Jordan (1), Algeria (1), Benin (1), Equatorial Guinea (1), Venezuela (1). Two people did not state the country they came from.

While all the participants do share a similar mission (to get education abroad), their life, time spent abroad, background, as well as their goals, dreams, aspirations and identity are not the same. At the same time, all study participants speak English as a second foreign language at a level not lower than upper-intermediate. Knowledge of the English language at the indicated level is necessary for a deep understanding of the interview questions and the ability to analyze the respondents' answers as instances of spoken discourse paying special attention to the rhythm and prosodic features. Undoubtedly they represent an important element of the respondents' narrative production and identity construction. Language proficiency was verified by the IELTS certificates being required at the stage of their enrollment.

The participants were students of the Bachelor's and Master's degree programmes at the Moscow State University of Food Production, RUDN University and the Higher School of Economics. The authors of the study 
and the interviewees did not know each other before the interview. There was a call for narrative research participants among foreign students at the Universities and therefore the respondents were recruited. Submission of the narratives was voluntary and the participants were made aware that they could be used for research purposes. In their instructions, participants were notified that anonymity would be followed.

\section{Instruments}

Semi-structured interview, included the following questions was used:

- Please, notify the main challenges you face during your first months in a new educational and cultural environment in Russia.

- $\quad$ Please, describe your feelings connected with these challenges. Try to describe all the challenges.Did you expect to face them? Why / Why not? Illustrate all the challenges you faced with examples. Comment on your ability to speak Russian. In your opinion, is it necessary for you to pay more attention to Russian for professional or everyday communication? Why?

- In your opinion, what measures do universities require to undertake to help foreign students during their adaptation period?

Having completed the interviews, we used an automated transcription service provider, Happy Scribe. ${ }^{1}$ When we got the transcription back we checked and edited it. For the purpose of our research we needed a very verbatim transcription so we checked every utterance to be transcribed in detail with all stutters, verbal tics ('like', 'uh'), and involuntary vocalizations (laughter).

\section{Methods and Approaches}

The analyses of the narratives of personal experiences elicited in research interviews were used to achieve the aim of this research.

\section{Polkinghorne's (1995) Concept of Paradigmatic Analysis}

By comparing similarities and differences between stories this type of analysis helps researchers to emphasise patterns in the narratives. The concept is based on coding to highlight the topics of talk and then sort topics into different categories in order to generate themes.

\section{Levels of Narratives Structure and Meaning Investigation}

We organized the text identifying the pitch glides so that every line features a central idea, articulated syntactically and intonationally. Then we grouped the lines into stanzas being somewhat larger groups about a single topic and capturing a single scene, a notional image on a specific event, claim, or piece of information. Following the Gee's (1991) approach we linked stanzas on the same topic to strophes and then to parts. When the basic stage was completed we identified the main line of the plot through the use of present tense verbs and non-subordinate clauses. The next level was focused on psychological subjects of the main sentences and represent points of view from which the material of a stanza is viewed and what the narrator emphasized in order to interpret the viewpoints expressed throughout the text. Then we highlighted the focused material (words, verbs, adjectives and rhetorical figures) of each stanza to interpret it thematically based on the previous levels of analysis. At this stage it was important to interpret and give sense to the whole structure of the text in terms of key images and themes.

\section{Evaluative Language Analysis}

As we worked with the transcribed narratives it was possible to capture rhythm and prosodic features of spoken discourse that can help in representing participants' identities and the meaning of their messages. Taking into consideration that languagepatternscanbegoodpredictors ofaspectsofhumanbehavior, we studied language features of the narratives focusing on utilized word-levellinguisticmodelsoffering a large spectrum of linguistic dimensions. The participants' feelings towards the challenges they face were interpreted through the analysis of evaluative language of the narratives. After W. Labov (1972) we considered evaluative language occurring throughout the narrative as the means used by a narrator to indicate the point of the narrative and to explain

\footnotetext{
${ }_{1}$ Interview Transcription. https://www.happyscribe.com/interview-transcription
} 
why the participants treated their experience of the challenges they faced in different ways. In this light, evaluation-bearing elements of language (modal system, grammatical mood, morphological structure, evaluative components of word meaning, etc) were examined.

\section{Procedure}

At the first stage of our study we analysed the relevant literature devoted to the barriers foreign students face in a new country (the results are presented in the introduction to the current paper). Thus we figured out the list of possible challenges.But we did not present them to the research participants in order to identify only those barriers that each of them faced in reality, without offering them "hypothetical" barriers that they may not have encountered.

At the second stage 42 foreign students were asked to recount their experience of coming to Russia to study and answer questions concerning barriers and challenges they face in the host country. Thus, 42 semi-structured interviews were conducted. These interviews were recorded for future transcription. All the questions were asked in English. The interview script consisted of a combination of questions of participants' background (age, sex, birth place, the length of their residence in Russia) and open-ended questions. To protect our respondents' namesand their personal information, we used pseudonyms.

The third stage was connected with the interpretation of the participants' responses to identify the challenges they faced. The participants were not given a list with specified challenges to match to their experience, although we had created the one based on the relevant literature. Our initial approach to analysis was deductive: having a set of codes based on an existing research framework we read through the transcripts and assign excerpts to codes. But then we realized that despite the fact that some of the barriers mentioned by the respondents correspond to the similar challenges we have identified in the analyzed sources, their content is strikingly different from those described by other researchers.

And then we turned to an inductive and iterative approach supported with paradigmatic analysis: we analyzed the transcripts, the literature and emerging themes to get a "best fit". At first, we read the narratives without commenting on or discussing them. After that each narrative was read independently. Now we identified key themes and sub-themes, moreover, we noted impressions and highlighted key quotations from the narratives. This approach allows not only to analyze the real barriers faced by foreign students, but to identify possible new barriers to adaptation caused by the pandemic or to localize the "new" content of "typical" barriers.

At the fourth stage of the study the linguistic features of the narratives were analyzed to identify the feelings towards the challenges foreign students face in the new cultural environment of the host society in the time of the pandemic.We analyzed narratives to identify a number of lexicogrammatical structures that can express evaluation in discourse: intensifiers and quantifiers, comparators, superlatives, hedges, negatives, questions, imperatives, and subordinators. We also studied adverbs, verbs, and adjectives of affect, certainty and doubt, explicitly evaluative and emotive lexis, emphatics, and modals. The analysis is supported with examples from narratives.

\section{Results and Discussion}

As a result of the analysis of narratives, we have identified an array of similar examples illustrating the barriers to efficient adaptation to the realities of studying in Russia specified by the research participants. The examples were categorized according to the frequency of presenting similar ideas to illustrate the experience of the described barrier. These examples are highlighted in italics and are presented after the colon at the end of the paragraph revealing one or another aspect of the analyzed barrier.

\section{Barriers to Adaptation of Foreign Students in the Host Society}

The analysis of narratives made it possible to record both the deeply studied barriers that foreign students face in most cases, and the barriers that have recently attracted the attention of researchers. The hierarchy of these barriers (from the most significant barrier to the least pronounced) in terms of their frequency are as follows: 
(1) the language barrier, (2) temporalities generated by the difficulties of the visa regime and bureaucratic delays associated with paperwork, (3) difficulties with adaptation and socialization and the psychological problems they generate, (4) difficulties with finding a job, (5) transition of classes to the online format and belonging to university in the time of the pandemic, (6) lack of understanding of teaching methods, (7) lack of a unversity councelling in solving routine issues, (8) discrimination on ethnic and cultural grounds, (9) difficulties with physical movement around the city due to the pandemic; (10) unpreparedness to study abroad.

\section{Language Barrier}

Problems related to poor knowledge of a foreign language of the host country have received widespread coverage in narratives. It is interesting that, in addition to its "traditional" understanding, this problem reveals new emphasises. Almost all survey participants indicated that they experience problems due to poor knowledge of the language of the host country. The linguistic barrier complicates almost all spheres of students' lives in the host country (socialization, adaptation, solving issues of daily life, employment, learning success, professionalization). The following statements are the most typical:

(1) One of the main challenges we face is learning the Russian language; (2) I have C1 level in Russian, but it is still too hard for me to understand the native people; (3) It is hard for me to understand my friends, especially jokes. That's why I started to talk with them less. I'm afraid of making silly mistakes; (4) I do not understand everything and becauseof insufficient knowledge of a foreign language, I have fears that I won't be able to acquire all the knowledge and skills to achieve success in my chosen profession.

At the same time, foreign students believe that solving the problem of the language barrier should not be their exclusive need. More than $50 \%$ of the study participants indicated that the population of the host country should speak English and stimulate communication with foreigners:

(1) The Russian people are good people. They are not racist, but they will not help you easily. Language is the big obstacle in adaptation. If the student learns the language well, he will overcome all obstacles, but Russian students should be directed to deal more with foreigners so that the language is taught faster; (2) I had a problem with the Russian language, and it is true that not everyone here knows English well.

Especially foreign students admit that considering the importance the export of education has for the economy and development of the country, administrative workers must be fluent in foreign languages:

(1) One of the biggest problems is the low level of the English language in Russia. After learning the language for only 4 months, I still can not communicate freely in Russian. That is still a problem because of the low level of English in the administration system. Big percentage of Russians are not even trying to communicate with foreigners; (2) If more workers in the administration would be bilingual, that would be great.

It should be noted that the research participants emphasize the need to revise the approach to overcoming the language barrier. Participants (75\%) indicated that during their preparation for training and their first year in the university, the main emphasis was on learning the language of professional and academic communication. Meanwhile, it is the lack of knowledge of everyday language that complicates socialization and adaptation to the realities of the host country as much as possible:

(1) Communication is better for me than professional learning; (2) I am at level B2(upper intermediate) and I think that I should pay more attention to academic Russian. I also should learn more street words to communicate more fluently with native speakers; (3) A lot of attention should be paid to speaking Russian for everyday communication; (4) I have C1 level Russian. But it seems like it is in professional communication, because I can easily understand lessons, events etc. But usually I do not understand what my friends are saying (or writing on telegram) even with help of translation; (5) I believe that there should be a course on colloquial expressions and intonations; (6) I would rather pay more attention to Russian for everyday communication. It's better to use English for professional communication.

The general concept of the importance of overcoming the language barrier has long been covered in an overwhelming number of studies on the topic (Grimshaw \& Sears, 2008; Green \& Mayatt, 2011; Podboj \& Lujić, 2020). Today, the emphasis on the importance of the purposeful study of the host country everyday language 
and the strategies for this study design is crucial (Canagarajah, 2013; Meniado, 2019). The requirement of foreign students that representatives of the host society should master the English language as the language of universal communication seems to be a new trend in the context of the export of education. The analyzed narratives allow us to state that foreign students in the times of the pandemic are becoming quite demanding to the host society. They consider themselves "accepted" with infringed rights, but being important actors in the development of society and the country (both the host and the native ones). Hence, the level of their exactingness towards the society of the host country also increases, including the way its representatives communicate with them (Abdulai et al., 2021). It is noteworthy that students from different countries showed similar expectations.

\section{Temporalities}

The phenomenon of temporalities as a part of experience of the need to wait for a visa and a work permit has been gaining its importance in recent years. At the same time, it has been little studied in relation to foreign students. In the meantime, it not only has a significant impact on their psychological state, but also shapes their expectations from the learning process in the host country. More importantly, the time constraints experienced by foreign students can drastically determine their primary professionalization as a result of studying at a university in the host country:

(1) The slow-track migration and document procedure took me a few weeks to complete; (2) There are a lot of bureaucratic procedures associated with the preparation of the necessary documents for legal residence in the country. The understanding of the inevitability of their extension and renewal already drives me into depression; (3) I faced slow administration work with big bureaucracy. All of the documents took more time than I expected; (4) The procedures, whether medical check-ups or migration, should take less time and have less bureaucracy; (5) The need for constant waiting ... I mean, paperwork for obtaining a visa and waiting for a decision on its provision, obtaining a residence permit in a hostel, for work.. all this stuff is painfully difficult for me. At such moments, I feel that the desire to do something and move somewhere is disappearing...

It is obvious that the visa regime is concerned with time: duration of the stay, the limit of work hours and the time spent on visa processing (Robertson, 2019), and these time restrictions change the perception of reality, their own capabilities, and transform plans. O. Mauri (2020) investigating the temporal forms of control engendered through the global border and visa regime and their impact on fragmenting the lives of foreign students named them temporal borders. It is clear that this is how time-related aspects of academic migration are perceived by the participants in this study. At the same time, temporary permits help to respond to shortterm labor market needs (Könönen, 2019), and permanent residency might facilitate transnational lifestyles and regular border crossing (Baas, 2015), which is extremely important in a situation of globalization of the labor market.

Temporalities also have a second dimension, which is practically not studied in connection with foreign students. We are talking about experienced temporalities (how time is lived, imagined and understood (Folke, 2018). $98 \%$ of the study participants noted a change in the perception of the speed of events during their stay in their home country, and during their studies at a university in the host country:

(1) I expected that the opportunity to study in another country would make me happy and open up new horizons for me. But everything is very slow. When I was in my country, it seemed to me that every day would be full of events. Now it seems to me that nothing is happening; (2) I am constantly faced with the need to combine my schedules: study schedule, work schedule, communication schedule with a family who lives in a different time zone. And every day it becomes more difficult for me. Everything seems blurry and unreal. Feeling tired. It's like I'm walking in a vicious circle. I have no energy left to study. It seems to me that nobody cares about me; (3) When I thought about my studies in Russia, I planned out every step I would take, built in my development strategies. But the reality is cruel. I can't do everything as planned. I am afraid that I am not ready to study abroad. Perhaps I chose the wrong specialization, since I am not able to complete everything according to the schedule.

Similar results were reported in the study by J.N. Folke (2018). The former states that there is much written on the acceleration of modern life, but little about slowness. According to M. Griffiths (2014), speed is fetishized, 
stillness and passivity tend to be considered as negative phenomena. The author depicts how migrants treat imbalance and powerlessness of the immigration system on the ground of four empirical temporalities: sticky time, suspended time, frenzied time and ruptured time. Uncontrollable chaotic experiences can be the result of change or movement deficiency. Paying attention to experienced temporalities can help students to anticipate new experiences in a new academic environment.

Uncontrolled experience of temporalities can reduce the motivation of foreign students to study, their potential adaptability to the realities of the host society, and, accordingly, reduce the potential for primary professionalization.

\section{Adaptation and Psychological Problems}

Adaptation to the realities of the host society and its culture, of course, requires psycho-emotional expenditures, giving rise to a feeling of insecurity, and, often, psychological / mental problems:

(1) The most difficult thing for foreign students is communicating with new people outside their homeland, due to different cultures. But foreign youth contributes to the development of the country in which they study, and not only in financial terms;(2) making friends wasn't, and still isn't easy. Culture and people are different in my country and in Russia. I came from a country where I had a lot of friends and people are genuinely polite there and here I sit in my apartment all day and have almost zero friends; (3) This generates uncertainty and a bit of fear, provokinga lot of emotions; (4) I fear that my inability to quickly adapt to new conditions of life will lead to a decrease in my success in the new country; (5) the culture of my country is very different from that of Russia. I fear that my otherness will prevent me from achieving maximum success, but I need help to adapt successfully. I am afraid to do something wrong, so I avoid any unnecessary actions. It depresses me. I am ashamed to discuss my fears with my fellows from my country. It is even more difficult for me to explain them to the Russians.

And again it is quite clear that the host society should change its attitude towards foreigners regardless of their country of origin and make efforts to optimize the process of their adaptation into culture and everyday life. The basic arguments are the importance of the export of education, the globalization of the international labor market and the creative potential of each specific newcomer in a situation of its efficient development:

(1) I think that finding new friends was a great challenge for me. Russians in general seem to me as pretty cold when it comes to communication. I wish they were more friendly; (2) Not only teachers but even students should try to help and should try to understand that for foreigners everything is not as easy as it is for them; (3) The lack of cooperation of Russians with foreigners students might decrease the potential ofthe export of education in Russia; People should demonstrate foreign students ways to adapt to local social environment.

Similar problems of adaptation are highlighted in a number of studies (Bethel et al., 2020; Chaiyasat, 2020; Ladum \& Burkholder, 2019), which emphasize students' experience in culture shock and associated acculturative stress, cultural adjustment, negative emotional responses and others, strategies that could enhance student-host connectedness during cross-cultural transitions. At the same time, it is obvious that foreign students today demonstrate a demanding attitude towards members of the host society, noting the need to jointly create a cooperative environment that can benefit both representatives of the newcomers and the host society (Bethel et al., 2020).

\section{Job Opportunities}

Almost all survey participants (96\%) indicated that it is much more difficult for a foreign student to find a job related to the acquired profession in the host country. The main area in which you can quickly find a job is the service sector (housekeeping, nursing, delivery, cleaning). The main problems concerning employment are associated with the host country language, difficulties in the preparation of documents, the need to obtain a work permit, lack of knowledge of the employment procedure and the need to synchronize incompatible work and study schedules:

(1) I think that I have fewer rights when looking for a job in Russia due to the rules for obtaining a residence permit; (2) have less rights in finding a job than someone who was born here, but I hope there will be opportunity for me to show my qualities and get a chance to have stable job 
in Moscow; (3) I think that I have less rights to get a good job that I can combine with my studies, I mean.. compared to Russian students. But if the university provided support at the stage of obtaining a part-time job, foreign students could strengthen their positions. Help is needed not only in the process of paperwork... We need training on passing job interviews, we need an analysis of the available labor market

Similar difficulties are experienced by students studying in other countries of the world. So, O. Maury (2020), in his study provides the following list of the most accessible job opportunities for foreign students in Finland: delivering newspapers, cleaning the rooms in hotels, serving fast food, the delivery service for the post office, etc. For example, there are some restrictions in the Russian legislation that make foreign students work only according to the profession specified in the permit. ${ }^{2}$

\section{Online Format of Education and Belongingto University}

The forced transition to online education, due to the COVID - 19 pandemic lockdown, complicates the life of foreign students in terms of educational success as well as in terms of adaptation to the host group, learning the Russian language and primary professionalization:

(1) The first thing concerns the online courses that we have no choice but to undergo; (2) We live in the time of the covid and the closing of borders. But it's also time to think about us foreigners. Taking classes online is very difficult. Also I have no opportunity to become a real part of my group; (3) Yes, we need to pay more attention to Russian language, because the studying online is different from studying physically, because studying physically we can communicate and interact with people and that will make us learn the language very fast; (4) I can't have the full experience online. I imagine that if my education were offline, my level of Russian would be better; (5) It is necessary to start lessons in person because online lessons are difficult to understand and many students complain about learning lessons online; (6) I cannot understand whether the choice of my future profession turns out to be correct, the online format of classes does not allow me to fully realize this. Due to the online format, it is line interaction. I do not like the online learning format, but I am glad that I have the skills to difficult for me to control my daily routine and be engaged; (7) if online classes are inevitable, universities should organize workshops to prepare students for classes in this format; (8) The pandemic has demonstrated that it is no longer possible to completely abandon online learning. Therefore, I am very glad that the school paid a lot of attention to work in a digital environment.

There is no doubt that not only foreign students experience difficulties in adapting to educational realities in the format of online learning. But there is also no doubt about the fact that for this category of students it turns out to be even more difficult than for students of the host society (Yıldırım et al., 2021). It is quite obvious that even after the end of the pandemic, reality will remain as digital as possible ${ }^{3,4}$, and it is necessary to develop the skills of efficient communication through the e- environment among students and teachers. Thus, Yildirim et al. (2021) believe that physical student mobility will decline in the next few years. And lots of offline courses have already transformed into online ones and their number will continue to grow. In fact, in the time of the pandemics hybrid education gives some opportunities for foreign students to continue their education using new technical tools and to have a chance not to lose their sense of belonging to their universities. At the same time, as H. Haugen and A. Lehmann (2020) noted in their commentary that the educational industry (on the example of Australia) feared that pivoting to digital education would decrease retention rates and willingness of the foreign students to pay full fees. It is quite evident that in the future it will acquire a hybrid format, but it is no less obvious that such a format requires appropriate training of students. The analysis of narratives revealed that some students are more ready for the online format than others. The latter statement is confirmed in a study by Aristovnik et al. (2020), who substantiated that the students' demographics have impact on the acceptance of online education and adaptation of new life standards: male, part-time, first-level, applied sciences, a lower living standard, from Africa or Asia were significantly less satisfied with their academic work / life during the crisis, whereas female, full-time, first-level students and students faced with financial problems were generally affected more by the pandemic in terms of their emotional life and personal circumstances.

Work opportunities for international students iRussia.https://studyinrussia.ru/en/life-in-russia/arriving-in-russia/job-for-students/

3 Mitchell, N. (May 7, 2020). "Students to decide which institutions survive COVID-19", available at: https://www.universityworldnews. com/post.php?story520200507135847614

4 Jørgensen, T. and Claeys-Kulik, A.-L. (february 6, 2021),“What does the future hold for Europe’s universities?”,available at: https://www. universityworldnews.com/post.php?story520210204091600372 
Online education gives students a sense of isolation from the university and its realities, a lack of understanding why the cost of education does not decrease due to the transition to the online format:

(1) Lack of access to university laboratories makes education a fiction, universities need to think over virtual reality tools, create remote laboratories and simulators. And, most importantly, you need to teach students how to use these tools; (2) Due to the online teaching format, I do not feel connected with the university. Now for me, this is a building that I have visited several times. I lack a sense of belonging; (3) Online learning is not as effective as offline learning. Why does the tuition fee stay the same? Universities should take this point into account; (4) The pandemic is likely to forever reshape the ways of educational interaction. It turns out that it is necessary to build new forms of interaction, think over new applications that allow the teacher to control the activities of students online. Foreign students need special online support. Maybe there should be tutors accompanying the online education of foreign students?; (5) If there is no access to face to face communication with students of the host university, it is necessary to create opportunities for workshops and seminars to overcome barriers in communication, so that online classes are efficient, everyone feels like members of a group, and we (foreign students) won't embarrass to participate in classes.

The results obtained maximally confirm the statement of Yıldırım and colleagues (2020) that university life consists of a sense of belonging relations among university students, academicians, physical campus and the identity value of the university. The online format of the educational process does not let all components of university life develop to the utmost, but offers new components that can form its new identity: interaction, participation, learning culture and support (Peacock et al., 2020). Students openly declare the relevance of the purposeful development of a new identity of the "student of the online format" as a tool for increasing the education efficiency.

\section{Educational Practice}

A significant part of the respondents (83\%) noted difficulties in understanding methods of teaching at the host university:

(1) I can not understand my chemistry teacher`s teaching method. I will be glad if she consultes me more; (2) I am worried about my studies. I can't understand the teaching approach. It is not similar to the one in my native country. Often think that I may fail the exam; (3) I'm not able to get used to the system of learning. It is difficult for me to complete hometask. I am not able to understand the material of learning.....It is really a challenge; (4) in a globalized world, it would be correct to create universal approaches to teaching and learning. Any of them should be understood to every student, regardless of his status, teaching methods would make it possible to better assimilate the studied material.

The European Union Association is developing the project "Universities Without Walls - a vision for 2030" to create the university of the future: a hybrid cross-border organization, which allows attracting much higher numbers of students, and combining physical and virtual facilities. ${ }^{5}$ The creation of a new model of higher education will also require universal approaches to teaching methods. At the same time, online learning / e-learning is becoming a mandatory teaching and learning process of educational institutions (Aristovnik et al., 2020). Moreover, researchers also note the need to develop a new culture of educational interaction, which requires the development of appropriate skills for both teachers and students (Peacock et al., 2020).

\section{University Counselling}

According to the research participants, the overwhelming number of barriers can be eliminated provided there is an efficient system of support for foreign students at the university level:

(1) We had to wait the whole day for our documents to be checked and accepted. And no one came from our university to pick us up from the airport and guide us the way to thehostel; (2) It was very difficult for me to draw up all the necessary documentation at the university: I did not understand how the system of a unified dean's office works and it was very difficult for me to

\footnotetext{
5 European Union Association. (2021). Universities without walls - A vision for 2030. https://www.eua.eu/resources/publications/957:universities-without-walls-\%E2\%80\%93-eua\%E2\%80\%99s-vision-for-europe\%E2\%80\%99s-universities-in-2030.html
} 
find the necessary rooms and classrooms; (3) Not all Russian universities do care about a preparatory year for foreign students. This is the most important year for a foreign student, and because the key to any country is its language in order to adapt faster, you must learn the language faster; (4) In my opinion, attention should be paid to exactly how everything is arranged at the university. How is the adaptation of foreign students organized, are the teachers ready to communicate with foreign students, are all procedures at the university transparent: will foreign students be able to deal with them?

The results of studies around the world have proved it. Foreign students are overeager about the lack of built-in support at the level of the university and its campus: from the development of a navigation route for a foreign student within the university, to the existence of structures that implement the preparation of foreign students for employment, visits to the clinic and specialists in psychological adaptation. In their studies, E. Tikhonova et al. (2021a, 2021b) analyze the possibilities of virtual reality as a tool for adapting foreign students to the realities of the host university and country. Moreover, virtual reality can be used to stimulate a digital learning environment for universities and students to be together in the same place regardless of wherever they are physically and with digital representations of themselves (Chi \& Idris, 2021). Also, it allows students to explore complex subjects when traditional teaching methods fail (Hamilton et al., 2021).

The research participants clearly emphasize the need to involve not only teachers and staff, but also students of the host university in the process of creating productive educational interaction:

(1) Universities should make more events in order to bring Russian students closer to foreign students; (2) Teachers should be nicer and considerate, that it is not our fault all this happened. It is so difficult to study under pressure. That's while there are so manyfailures from our side. We want to study but only the University can help foreign students; (3) I think universities should increase the number of speaking clubs where foreign students have a chance to speak with natives; (4) Students are instructed to deal more with foreign students and there should be specific hours each day when foreign students talk to some Russian students to strengthen their language so that they adapt faster; (5) A crash course in cultural differences and local manners will be of of great use; (6) They should have accommodated foreigners in one hostel. Since no one will be local, everyone will have to communicate with each other; (7) The university must put in every department people who speak several languages.

Perceiving themselves as active actors of academic mobility and the modern educational landscape, students persistently emphasize the need for the host environment to be ready to build effective interaction. Quite similar results are demonstrated in the works of S. Ünal (2017) who believes that both the developed and developing countries should make new plans, develop new strategies and cooperate in terms of foreign students 'adaptation. Abdulai et al. (2021) state that the chance for foreign students to adapt to a host country culture will be influenced by the host country's receptivity, conformity of the migrant students to the host cultures, and the presence and organization of other home culture members. Thus, M, Ozios and P. Pasque (2019) considers the university administrators as being responsible for equality, social justice and positive public attitude in the dialogue between foreign students and the representatives from the host society.

\section{Discrimination}

Cases of discrimination in the analyzed narratives are represented by an extremely limited number of participants (2\% of participants):

(1) I can't say that there is a fear of Muslim people. But there is a wrong prediction about the Uzbek people. Because most of the people who are coming from my country are immigrants who didn't have full education, they misbehave. So, among other people goes such a thought that all Uzbek people are coming from villages and even think that Uzbekistan is the same country as Afghanistan. Which none of these kinds of assumptions are right; (2) I had problems with racism because of the fact that I'm Arab; (3) I faced discrimination, only because I am not Russian; (4) Not all of the Russians are racists, the majority of people there show to the foreign student that they are accepted in Russia and not under discrimination because of their nationality, color of the skin, politics in his/her country, tradition, culture etc.

In a significant number of completed studies, the problem of discrimination resulting in the stigmatization of consciousness is mentioned by students in the first place (Ünal, 2017; Poyrazli \& Grahame, 2007). The 
pandemic, however, has pushed the problems of discrimination to a secondary level, updating the barriers activated by the pandemic. In the time of the pandemic foreign students are anxious about their future andhave to consider all the consequences of leaving their country of study to go back to their native country and possibly be locked out indefinitely. They claim a flexible visa regime, emotional support and counselling on behalf of the universities, moreover, they want the citizens of the host society to stop asking them when they are going to come back home because of the spread of COVID-19. ${ }^{6}$ In our study, direct discrimination was not reported, but still there is some evidence that in other countries foreign studentd remain the subjects of the prejuduced attitude and agression. A.C. Balingue (2021) reported that fear of COVID-19 has escalatedsocial discrimination and hate crimes towards studetns from Asian region, especially from China.

Mobility restrictions due to lockdown measures turned out to be quite "new" for students:

(1) I don't want the borders to get closed because it might prevent us from going back and forth to our homeland; (2) I'm having a hard time moving around; (3)Having friends is also hard because most of them live far from the centre; (4) I think I will return to my country, because the world is now in a very difficult situation due to the pandemic; (5) It seems to me that it is more correct today to choose a university in your native country or neighboring countries for training. Then the pandemic will not lead to a long separation from your relatives, and if everything goes worse, I mean epidemiological situation, it will be easier to return home.

Restrictions in movement have led to disastrous results for academic mobility. For example, in Finland, 90\% of students participating in academic exchange programs in 2020 decreased their mobility. ${ }^{7}$ At the same time, foreign students faced challenges both in education and work due to restriction of mobility. ${ }^{8}$ Specifically, the inability to work during the pandemic frustrates students from less developed countries, who believe that their opportunity to study abroad can be the start of their careers. Moreover, there is also a redistribution of the academic mobility geography. Thus, after the pandemic, students from China and Hong Kong prefer universities in the Asian region (Taiwan, Japan, etc.) as opposed to universities in Europe and the USA (Xiong et al., 2020).

\section{Unpreparedness to Study Abroad}

The arguments of foreign students about the self-exactingness appeared to be very interesting. More than 73\% of respondents noted that education abroad requires targeted preliminary preparation both at the level of learning the language of the host country and at the level of developing soft skills:

(1) Having decided to get higher education in Russia I have finished a special school of Russian in my country. And now I don't have any problem with Russian language; (2) Studying, and especially studying in another country, requires relying on the developed skill of planning your time. Only the correct time management will allow me to achieve the goals that I set for myself in relation to my future; (3) I feel that I do not have the skills that are necessary to successfully study abroad. I am not sufficiently familiar with the culture and the Russian language, I have not learned to think critically: I feel that emotions often prevail over reason. I am really bad at time management. It's a pity that I didn't bother to develop these skills when I was in my homeland. Now there is also a quarantine. I'm afraid I will have to return to my homeland and study at the university there.

A relatively new trend associated with student mobility has turned out to be a deep awareness of the fact that entering a foreign university is not equal to successful professionalization. Studying at a university in a foreign country requires additional effort and is associated with psycho-emotional complexities, and therefore requires a set of formed soft skills. Personality is associated with definite traits, aims and motivation.In the context of the labor market, they can be considered a significant added value that increases employee success (Rego et al., 2016). In the same way, they increase the potential of the student in the context of primary professionalization.

\footnotetext{
6 Chikaonda, G. P. (November 5, 2021). Far and away. https://www.insidehighered.com/views/2021/11/05/challenges-international-students-during-covid-opinion

7 Finnish National Agency for Education. (2020). Impact of COVID-19 on higher education student mobility in Finland. https://www.oph. fi/en/news/2020/impact-covid-19-highereducation-student-mobility-finland

8 European Commission. (2020). Inform \# 2 - impact of COVID-19 on international students in EU and OECD member states series of EMN-OECD informs on the impact of COVID-19 in the migration area. https://ec.europa.eu/homeaffairs/sites/homeaffairs/files/00_eu_ inform2_students_final_en.pdf
} 
For a foreign student, the developed soft skills optimize the process of his adaptation to the realities of the host society as much as possible.

\section{Experiences of Barriers to Adaptation by Foreign Students: Evaluative Language Analysis}

This section presents the emotional reactions of foreign students regarding the difficulties they faced in the host country institution through the analysis of their language. The relation of the rational assessment and the emotional subtext of the statement makes it possible to implement the double check of the statements content.

Expressing feelings is a difficult part of verbal communication. Standards and norms for emotional expression could also vary based on nationality and other cultural identities and characteristics. Despite the fact that expressing feelings is more complicated than other forms of expression, emotion sharing is an important part of how we create social bonds and empathize with others, and it can be improved.

It should be noted that the English language in this study is a means of communication and the foreign students not being native speakers of it can't represent all the peculiarities of the language. But still, their knowledge of English at the upper-intermediate level lets us consider that they have acquired some features of the English linguaculture. In English culture, open expression of emotions is not encouraged, restraint and self-control are considered the main features of decent behaviour (Wierzbicka, 1999). Perhaps this is why emotions in English are often expressed implicitly. The implicit means of conveying emotional information in English discourse include the means of grammar, among which we can single out, for example, modal verbs (Pounds, 2015; Hidalgo-Downing, 2015).

\section{Evaluation of the University Activities Focused on Foreign Students' Adaptation}

Having studied the narratives, it was found that the mostly used means of evaluation-bearing elements of language revealing foreign students' attitude towards the challenges they face in the new environment of the host society was modality. In addition to such meanings as obligation, necessity, prohibition, permission, opportunity, etc., modality units often express the speaker's emotional attitude to the communicated (Ozyumenko, 2015). In parallel with the implementation of primary and secondary functions, these modal units act as a means of transmitting various emotional information.

Most foreign students expressed their emotional attitude and feelings towards measures universities required to undertake to help foreign students during their adaptation period through the use of modal verbs:

... should give more time for students to learn the Russian language properly; should help us

to better master the language, should help us in the process of establishing the necessary

living conditions to live in Russia; should give us another chance to learn the Russian language

It is clear that 'should' is used here to express thoughts or advice, in other words, foreign students tell another person to do as they want. In this usage it is very similar to 'must', and even translated in the meaning of «must», however, it was pronounced with a softer intonation and less categorical. As a result, there is no strict motivation for action, there is only advice, although it can be and sounds urgent, even to the point of necessity:

... should be more flexible and try to help more; should take less time and have less bureaucracy; should increase the number of speaking clubs where students have a chance to speak with natives

\section{Problems with Communication Evaluation}

Moreover, the inability of foreign students to communicate effectively in the national language (Russian) used in the universities might affect their adaptation and integration into the host universities and communities. They believe it happens because most public servicesprovide information only in their main national language which may limit the ability of migrants to assess essential public services:

... must put in every department people who speak several languages;

In this example it is seen that here 'must' emotionality overshadows obligation, which makes it possible to use this modal verb for conveying advice or recommendation. The use of comparatives and superlatives is also considered as a way to express foreign students' feelings and evaluation : 
... one of the biggest problems is the low level of the English language in Russia; more flexible stuff; less time and less bureaucracy; life in Moscow is better than the life I had

\section{Complains about the Lack of Assistance}

It was found out that foreign students from the Global South (21\%) turned out to be more exacting than students from ex-Soviet Central Asia. They complain that they have to survive without any assistance from the university administration expressing themselves, again, using modals and comparatives:

... you need to survive by yourself; the teachers to be more nicer and considerate; have to stay alone and survive in such a big city as Moscow

Their use of 'should' in combination with a perfect infinitive expresses criticism and reproach toward the university facilities service:

... the administration should have accommodated students of different nationalities together as they could communicate with each other; someone should have met us at the airport

\section{Evaluation of the New Learning Environment}

The differences in teaching and learning methods might pose some challenges to foreign students' adaptation and integration into the host universities academic cultures during the first year of their studies. Following Y. Kim (2000) we believe that students are often entangled with issues that are usually taken for granted and start feeling anxiety in their new learning environment and societies. We also agree with Abdulai et al (2021) who state that when people are anxious because of the new learning environment, they start to feel awkward and pay attention to minor issues. The participant convey frustrations and evaluation through the use of explicitly evaluative language, particularly adjectives (Pounds, 2015):

The only thing that made me anxious was the slow-track migration and document procedure; I am still very anxious about my studies, about the process to issue the visa; the border and slow migration is disheartening; don't want to look dumb in front of my teachers and other students; preparing documents was very hard and stressful process; I am underinformed

... very hard to study; very complicated as well; everything is so bad;quite difficult for me;a little bit difficult in especially a cultural way

\section{Shattered Expectations}

Abdulai et al. (2021) insist that academic cultures in the host universities can either be a resource or an enabler for the integration and adaptation of foreign students into the host universities, or a barrier for their inability to efficiently adapt and integrate into the host universities teaching and learning cultures. And we can't agree more that this is because culture is shaped by beliefs, attitudes, values, experiences, norms, behaviours, worldviews, which become entrenched over time. Their expectancies are triggered by the expressions of uncertainty and emotive stances (Pounds, 2015):

I came from a country where I had a lot of friends and people are genuinely polite; Moscow is really expensive; everything in my country is absolutely different; we are quite well known for our generosity, we have many foreigners and we treat them in a good way; I was expecting that people in Moscow would be as polite as my uzbek people who live in Uzbekistan

Abdulai et al. (2021) have already proved that people usually filter both verbal and non-verbal messages using their own cultures and evaluate host cultures comparing them to their own as the benchmark or standard.

These utterances reveal discriminatory treatment based on negative perceptions about an individual's country of origin and its culture. What is good to note is that cultural expressions are embedded with some degree of ethnocentrism (Kim, 2001).

... being a foreigner is a little hard ; they don't speak English quite well; I truly believe that the russian teaching department is simply spectacular

The fact that facilitating interaction between foreign students and students from the host country both inside and outside the classroom improves their adaptation into the host university, enhances their communication 
and cognitive skills, and as well as cultural awareness (King et al., 2017). In our study students feel loneliness and disappointment because they can't make friends due to the language barriers and their status marked by the use of hedges and boosters:

... finding new friends was sort of a great challenge for me; I'm definitely not the only one that has a problem with making friends here; they probably don't want to communicate with a new person outside of their circle.

Moreover, modal expressions with the meaning of the desired action are used to denote frustration and unrealizability (Ozyumenko, 2015):

I wish they were more friendly; if only I didn't sit in my apartment all day and had almost zero friends; I wish they would help.

\section{Problems with Language}

Following Heggins and Jackson (2003) studying challenges of Asian students' adaptation and integration in US Midwestern University we found out that foregn students in Russia also encountered barriers related to language proficiency. This inability and a lack of confidence in their communication skills hindered their adaptation into the host culture. The research carried out by Abdulai et al. (2021) proves that foreign students believe they could also increase their access to important information and public services at the host universities and communities knowing the Russian language better. The respondents used the means of modality reporting their feelings about the Russian language and their ability to communicate in it:

... should pay more attention to academic Russian; should learn more street words to communicate more fluently with native speakers; should focus myself on learning a higher level of Russian;there should be a course on colloquial expressions and intonations;but Russian students should be directed to deal more with foreigners so that the language is taught faster.

... need to focus more on Russian for professionals because I need it for the specialty I've chosen; need practice to talk; need to pay great attention to the Russian language to receive the largest amount of knowledge.

\section{Attitude towards Ddiscrimination}

The findings of Lee and Rice (2007) discovered that students from Asia, Africa, South America, and the Middle East experienced discriminatory treatment in the form of verbal attacks and other direct confrontation in the learning environments in most universities in the USA. In our study, foreign students do not point out a direct discrimination but speak about overall hostility towards them. Again, the use of intensifiers, comparators, boosters, hedges and attitudinal (meta)-discourse markers reveal the respondent's feelings through the evaluation:

I truly got a culture shock about the people; of course, I don't think that all Russian people are mean; they don't respect foreigners like before and they have actually an evil attitude with us as foreigners; I'm afraid of making silly mistakes and it seems like that people not always keen on to explain you something twice; people absolutely forgot about simple politeness and humanity;

... people were pretty cold; less smiling; extremely nice.

Negatives, questions and subordinate that-clauses can also convey the degree of their despair:

I agree that not all of the russians are racists; surely, they are not under discrimination because of his/her nationality, color of the skin, politics in his/her country, tradition, culture etc; it is not our fault thatall these happened so why pressure and fail us so much?; they are not racist, but they will not help you easily.

Also, foreign students use the verb 'need' to denote advice, not necessity:

... need to focus more on teaching students the language depending on their major 


\section{Uncertainty in Finding a Job}

Although foreign students are increasingly welcomed into higher education in Russia, the hospitality of the host nation and institution remains conditional, and contested. Foreign students are worried about this fact and believe that in Russia, as in some EU countries, migration issues are based on the perception that foreigners represent a potential threat to the local labour markets and should be controlled (Stein \& Andreotti, 2016). This belief is reflected in their responses and is highlighted by the use of nonpropositional evaluative resources that can be seen to fulfill a specific evaluative function, among them boosters and comparatives being quite notable (Pounds, 2015):

I have less rights to have a job here because of residence permit policies; of course, I will have less rights in finding a job than someone who was born here; in fact, as a foreigner I won't have good opportunities to express myself; I think we have fewer rights to find a job in Russia because of residence permit policies; I think that I have fewer rights when looking for a job in Russia due to the rules for obtaining a residence permit.

\section{Restrictions due to the Pandemic}

In times of the pandemic foreign students as well as students from the host society have to take on new roles, adapt to new technologies and new strategies of communication. For many of them it turned to be a new challenge, in this case they convey theevaluation explicitly:

Online lessons are difficult to understand and many students complain about learning lessons online; via online I only achieved the basic command of the language.

Moreover, the whole situation of closed borders and vague future perspectives make students feel anxious and be uncertain:

So it's complicated because the pandemic is so uncertain; with the time of the covid and the closing of borders, now it's time to think about us. We follow the courses poorly and under informed; the pandemic had the lion's share of heartache.

\section{Positive from the Very Beginning}

Despite all the difficulties not all the students express negative feelings, some of them (29\%) are really happy and use evaluative and emotive lexis:

I feel privileged to be here; ... my classmates in a group, I feel the spirit of help and understanding; I am happy to be with them.

The analysis above revealed evaluative meaning associated with certain expressions that typically collocate with either positive or negative words, common grammatical patterns associated with evaluative meaning to be a good marker in studying foreign students' feelings towards new challenges they face in the new cultural and academic environment in the host country. The ability to recognize hidden emotional shades that the speaker wants to convey in his utterance, to adequately interpret his communicative intention, in other words, to see his pragmatics behind the semantics of the utterance, is of great importance in intercultural communication. And emotional competence proves to be a crucial and an integral part of intercultural communicative competence (Ozyumenko, 2015).

\section{Limitations of the Study}

We limited our study to a small segment of educational migrants mostly from Arab,Asian and African countries, but there were few students from European countries. So, that remains unclear how students from other countries and cultural contexts would relate with these findings, and that can be treated as an issue offuture research. Such research could broaden the scope of the study and cover other geographical areas and migration contexts.

Only the first year students (bachelors and masters) participated in our study in order to track exactly the experience of initial adaptation. Accordingly, it is necessary to track the same aspects at each year of study in order to trace the transformation of these barriers perception. 
Due to the fact that the focus of the research was on the first-year students, the empirical fieldwork did not include the economic dimension of foreign students`integration and adaptation processes. None of the respondents dwelled on this aspect directly. Meanwhile, the ability of earning money and specifically as a result of primary professionalization (being the economic measurement of the success of part-time work during the period of study at the university within the studied profession), can significantly determine the efficiency of a foreign student's adaptation not only to new academic environments, but also to hosting communities. Hence, this aspect requires close study, especially in dynamics (to trace the change in their perception from the first to graduation courses).

\section{Conclusion}

The purpose of this study was to track changes in the foreign students' perception of traditional barriers to adaptation to the realities and university of the host country, as well as to identify new barriers due to the impact of the COVID-19 pandemic. An analysis of narratives of the first-year foreign students (seeking for a bachelor's or a master's degree) who had not previously visited Russia made it possible to: (1) identify the real barriers that foreign students faced in 2021 in the beginning of their studies in the host country; (2) analyze the hierarchy of barriers from the point of view of real actors of academic mobility; (3) analyze their new understanding to specify whether the perception of traditional barriers has changed; (4) to identify new challenges for international students posed by the pandemic; (5) to compare the rational attitude of students to the described barriers, with their emotional perception.

The data obtained indicate the change in the usual hierarchy of barriers to adaptation of foreign students. Thus, the problems of discrimination and the psychological aspects associated with it have shifted from the leading positions to the last lines of the "top list". At the same time, the language barrier still remains at the head of the list, determining, in many respects, the severity of the remaining barriers. Temporalities, which were previously identified as a barrier by individual students and researchers, took the leading position. In addition, foreign students began to view the online learning format and physical travel bans as significant challenges in the process of adapting to the realities of the host society. Considerable attention is paid to the feeling of foreign students' identification with the university during the pandemic. Hence, it becomes necessary to develop new tools for developing this identity and to work out in detail its content. This need becomes even more urgent due to the conclusions of the researchers about the inevitable transition to hybrid educational models after the end of the pandemic. In our opinion, it is also important that foreign students understand the fact that studying abroad requires additional and purposeful preparation, the development of a number of soft skills. And it is the student who ought to take responsibility for this preparation. It should also be noted that students understand the importance of the export of education for any country, hence they are more demanding about the support that the host university is ready to provide and the strategies of communication between the host population and the students from other countries.

Linguistic analysis of narratives demonstrated the coincidence of the rational description of the challenges faced by the research participants with their emotional experience. The latter reflects the desire «to be true to oneself» and to overcome the barriers and not consider them as invincible obstacles.

Further, it is necessary to trace the transformation in the perception of the analyzed barriers by foreign students from course to course, based on the logic of changes in the educational landscape caused by the consequences of the COVID-19 pandemic.

\section{Conflict of Interest}

The authors declare no conflict of interest. 


\section{References}

Abdulai, M., Roosalu, T., \& Wagoner, B. (2021). Cultural barriers and enablers of integrating educational migrants from the Global South: The case of graduate students in Europe. International Journal of Educational Development, 86, 102479. https://doi.org/10.1016/j.ijedudev.2021.102479

Alemany-Arrebola, I., Rojas-Ruiz, G., Granda-Vera, J., \& Mingorance-Estrada, Á. C. (2020). Influence of COVID-19 on the perception of academic self-efficacy, state anxiety, and trait anxiety in college students. Frontiers in Psychology, 11, 570017. https://doi.org/10.3389/fpsyg.2020.570017

Aleschanova, I. V. (2006). Narrativnost': Opredelenie ponyatiya [Narrative: Defining a concept]. Izvestiya Volgogradskogo gosudarstvennogo pedagogicheskogo universiteta, (3), 43-47.

Aristovnik, A., Kerzic, D., Ravselj, D., Tomazevic, N., \& Umek, L. (2020). Impacts of the COVID-19 pandemic on life of higher education students: A global perspective. Sustainability, 12(20), 8438. https://doi.org/10.3390/ su12208438

Baas, M. (2015). The fluidity of return: Indian student migrants' transnational ambitions and the meaning of Australian permanent residency. In M. Baas (Ed.), Transnational migration and Asia: The question of return (pp. 39-54). Amsterdam University Press.

Baas, M., \& Yeoh, B. S. (2019). Introduction: Migration studies and critical temporalities. Current Sociology, 67(2), 161-168. https://doi.org/10.1177/0011392118792924

Baker, S., Due, C., \& Rose, M. (2021). Transitions From education to employment for culturally and linguistically diverse migrants and refugees in settlement contexts: What do we know? Studies in Continuing Education, 43(1), 1-15. https://doi.org/10.1080/0158037X.2019.1683533

Balant,e J., van den Broek, D., \& White, K. (2021). How does culture influence work experience in a foreign country? An umbrella review of the cultural challenges faced by internationally educated nurses. International Journal of Nursing Studies, 118, 103930. https://doi.org/10.1016/j.ijnurstu.2021.103930

Balingue, A. C. (2021). Countering social stigma and discrimination during the COVID-19 pandemic through solidarity. Journal of Public Health, 43(2), e399-e400. https://doi.org/10.1093/pubmed/fdab052

Bamberg, M. (2012). Identity and narration. In P. Hühn, J. C. Meister, J. Pier, \& W. Schmid (Eds.), The living handbook of narratology. Hamburg University. http://www.lhn.uni-hamburg.de/article/identity-and-narration

Belford, N. (2017). International students from Melbourne describing their cross-cultural transitions experiences: Culture shock, social interaction, and friendship development. Journal of International Students, 7(3), 499521. https://doi.org/10.32674/jis.v7i3.206

Béligon, S. (2019). Feeling, emotion and the company they keep: What adjectives reveal about the substantives. Lexis, 15, 1-25. https://doi.org/10.4000/lexis.4322

Bell, J. S. (2002). Narrative inquiry: More than just telling stories. TESOL Quarterly, 36(2), 207-213. https://doi. org/10.2307/3588331

Bello, V. (2021). Normalizing the exception: Prejudice and discriminations in detention and extraordinary reception centres in Italy. International Politics. https://doi.org/10.1057/s41311-021-00290-8

Bethel, A., Ward, C. \& Fetvadjiev, V. H. (2020). Cross-cultural transition and psychological adaptation of international students: The mediating role of host national connectedness. Frontiers in Education, 5, 539950. https://doi.org/10.3389/feduc.2020.539950

Boland, C. (2020). Hybrid identity and practices to negotiate belonging: Madrid's Muslim youth of migrant origin. Comparative Migration Studies, 8, 26, 1-17. https://doi.org/10.1186/s40878-020-00185-2

Canagarajah, S. (2013). Skilled migration and development: Portable communicative resources for transnational work. Multilingual Education, 3(1), 8, 1-19. https://doi.org/10.1186/2191-5059-3-8

Céspedes, C., Rubio, A., Viñas, F., Cerrato, S. M., Lara-Órdenes, E., \& Ríos, J. (2021). Relationship between selfconcept, self-efficacy, and subjective well-being of native and migrant adolescents. Frontiers in Psychology, 11, 620782. https://doi.org/10.3389/fpsyg.2020.620782

Chaiyasat, C. (2020). Overseas students in Thailand: A qualitative study of cross-cultural adjustment of French exchange students in a Thai University context. Journal of Human Behavior in the Social Environment, 30(8), 1060-1081. https://doi.org/10.1080/10911359.2020.1792386

Chi, P. G., \& Idris, M. Z. (2021). Employing Virtual Reality (VR) technology with experiential learning perspective to enhance students' learning experience. International Journal of Academic Research in Business and Social Sciences, 11(4), 650-655. http://dx.doi.org/10.6007/IJARBSS/v11-i4/9712

Consoli, S. (2021). Uncovering the hidden face of narrative analysis: A reflexive perspective through MAXQDA. System,102, 102611. https://doi.org/10.1016/j.system.2021.102611

Denzin, N. K., \& Lincoln, Y. S. (Eds.). (2005). The Sage handbook of qualitative research (3rd ed.). Sage Publications Ltd. 
Folke, J. N. (2018). Moving on or moving back? The temporalities of migrant students' lived versus imagined school careers. Journal of Ethnic and Migration Studies, 44(9), 1506-1522. https://doi.org/10.1080/136918 3X.2017.1329008

Gee, J. P. (1991). A linguistic approach to narrative. Journal of Narrative and Life History, 1(1), 15-39. https://doi. org/10.1075/jnlh.1.1.03ali

Glace, A. M., Dover, T. L., \& Major, B. (2021). Latinx identity and intersectional responses to stigma. Cultural Diversity and Ethnic Minority Psychology, 27(4), 593-601. https://doi.org/10.1037/cdp0000456

Gonta, I., \& Bulgac, A. (2019). The adaptation of students to the academic environment in university. Revista Romaneasca Pentru Educatie Multidimensionala, 11(3), 34-44. https://doi.org/10.18662/rrem/137

Green, W., \& Myatt, P. (2011). Telling tales: A narrative research study of the experiences of new international academic staff at an Australian university. International Journal for Academic Development, 16(1), 33-44. https://doi.org/10.1080/1360144X.2011.546219

Griffiths, M. (2014). Out of time: The temporal uncertainties of refused asylum seekers andimmigration detainees.Journal of Ethnic and Migration Studies, 40, 1991 - 2009. https://doi.org/10.1080/136918 3X.2014.907737

Grimshaw, T., \& Sears, C. (2008). 'Where am I from?', 'Where do I belong?': The negotiation and maintenance of identity by international school students. Journal of Research in International Education, 7(3), 259-278. http://dx.doi.org/10.1177/1475240908096483

Gritsenko, V. V., Khukhlaev, O. E., Zinurova, R. I., Konstantinov, V. V., Kulesh, E. V, Malyshev, I. V., Novikova, I. A., \& Chernaya, A. V. (2021). Intercultural competence as a predictor of adaptation of foreign students. CulturalHistorical Psychology, 17(1), 102-112. https://doi.org/10.17759/chp.2021170114.

Hamilton, D., Mckechnie, J., Edgerton, E., \& Wilson, C. (2021). Immersive virtual reality as a pedagogical tool in education: A systematic literature review of quantitative learning outcomes and experimental design. Journal of Computers in Education, 8(1), 1-32. https://doi.org/10.1007/s40692-020-00169-2

Hari, A., Nardon, L., \& Zhang, H. (2021). A transnational lens into international student experiences of the COVID-19 pandemic. Global Networks, 1-17. https://doi-org.proxylibrary.hse.ru/10.1111/glob.12332

Harvey, R. D. (2001). Individual differences in the phenomenological impact of social stigma. The Journal of Social Psychology, 141(2), 174-189. https://doi.org/10.1080/00224540109600545

Haugen, H.Ø., \& Lehmann, A. (2020). Adverse articulation: Third countries in China-Australia student migration during COVID-19.Dialogues in Human Geography, 10(2), 169-173. https://doi.org/10.1177/2043820620934939

Heggins, W. J. III, \& Jackson, J. F. L. (2003). Understanding the collegiate experience for Asian international students at a Midwestern Research University. College Student Journal, 37(3), 379-391.

Hidalgo-Downing, L. (2015). Grammar and evaluation. In C. A. Chapelle (Ed.), The encyclopedia of Applied Linguistics (pp. 1-8). John Wiley \& Sons, Ltd. https://doi.org/10.1002/9781405198431.wbeal1471

Kamalova, L. A., Umbetova, M. Zh., \& Putulyan, N. S. (2021). Technologies and practices of linguistic and sociocultural adaptation of foreign students during their studies at the university. Contemporary Educational Technology, 13(1), ep288. https://doi.org/10.30935/cedtech/9312

Karim, S., Hue, M. T., \& Ullah, R. (2021). Acculturative challenges among Pakistani secondary school students in Hong Kong. International Journal of Intercultural Relations, 82, 1-11. https://doi.org/10.1016/j. ijintrel.2021.02.006

Kim, Y. Y. (2000). Becoming intercultural: An integrative theory of communication and cross-cultural adaptation. Sage Publications.

King, R., Lulle, A., Sampaio, D. \& Vullnetari, J. (2017) Unpacking the ageing-migration nexus and challenging the vulnerability trope. Journal of Ethnic and Migration Studies, 43(2), 182-198. https://doi.org/ 10.1080/1369183X.2016.1238904

Könönen, J. (2019). Becoming a 'labour migrant': Immigration regulations as a frame of reference for migrant employment. Work, Employment and Society, 33(5), 777-793. https://doi.org/10.1177\%2F0950017019835133

Kowalska, M., Zięba, M., \& Wiecheć, K. (2021). The narrating self and the experiencing self in the narratives of women who have experienced trauma. Journal of Constructivist Psychology, 1-20. https://doi.org/10.1080/10 720537.2020 .1865221

Labov, W. (1972). The transformation of experience in narrative syntax. In W. Labov (Ed.), Language in the inner city: Studies in the black English vernacular (pp. 354- 396). University of Pennsylvania Press.

Ladum, A., \& Burkholder, G. J. (2019). Psychological adaptation of international students in the northern part of Cyprus. Higher Learning Research Communications, 9(1), 28-46. http://dx.doi.org/10.18870/hlrc.v9i1.436

Lee, J. J., \& Rice, C. (2007). Welcome to America? International student perceptions of discrimination. Higher Education, 53(3), 381-409. https://doi.org/10.1007/s10734-005-4508-3 
Maury, O. (2020). Punctuated temporalities: Temporal borders in student-migrants' everyday lives. Current Sociology. https://doi.org/10.1177/0011392120936315

Meniado, J. C. (2019). Second language acquisition: The case of Filipino migrant workers. Advances in Language and Literary Studies, 10(1), 47-57. https://doi.org/10.7575/aiac.alls.v.10n.1p.47

Moussa, N. M. (2021). International students' achievements and adaptation to the United States' culture. Qualitative Research Journal, 21(4), 498-512. https://doi.org/10.1108/QRJ-11-2020-0145

Murillo, E. G. (2002). How does it feel to be a problem? Disciplining the transnational subject in the American South. InS. E. F. Wortham, E. G. Murillo Jr., Edmund T., \& Hamann (Eds.), Education in the new latino diaspora (pp. 215-240). Greenwood Publishing Group.

Norton, B. (2013). Identity and language learning. Extending the conversation (2nd ed.). Multilingual Matters. https://doi.org/10.21832/9781783090563

Ozias, M., \& Pasque, P. (2019), Critical geography as theory and praxis: The community-university imperative for social change. The Journal of Higher Education, 90(1), 85-110. https://doi.org/10.1108/HEED-01-20210014

Ozyumenko, V. I. (2015). Grammatical means of expressing emotions in English discourse. Russian Journal of Linguistics, (1), 126-143.

Peacock, S., Cowan, J., Irvine, L., \& Williams, J. (2020). An exploration into the importance of a sense of belonging for online learners. International Review of Research in Open and Distributed Learning, 21(2), 18-35.

Podboj M., \& Lujić, R. (2020). Living in the "in-between": Narrative inquiry into investment of foreign language teachers teaching abroad. Komunikacija i kultura online, 11(11), 189-225. https://doi.org/10.18485/ kkonline.2020.11.11.11

Polkinghorne, D. E. (1995). Narrative configuration in qualitative analysis. International Journal of Qualitative Studies in Education, 8(1), 5-23. https://doi.org/10.1080/0951839950080103

Pounds, G. (2015). Evaluative language. In K. Tracy, T. Sandel, \& C. Ilie (Eds.), The international encyclopedia of language and social interaction (pp. 1-6). John Wiley \& Sons, Ltd. https://doi.org/10.1002/9781118611463. wbielsi063

Poyrazli, S., \& Grahame, K. M. (2007). Barriers to adjustment: Needs of international students within a semiurban campus community. Journal of Instructional Psychology, 34, 28-45.

Rego, R., Zózimo, J. R., Correia, M., \& Ross, A. (2016). Bridging volunteering and the labour market: A proposal of a soft skills matrix. Voluntary Sector Review, 7, 89-99. https://doi.org/10.1332/204080516X14537236936186

Robertson, S. (2019). Migrant, interrupted: The temporalities of 'staggered' migration from Asia to Australia. Current Sociology, 67(2), 169-185. https://doi.org/10.1177\%2F0011392118792920

Selvitopu, A. (2020). Exploring the lived social and academic experiences of foreign-born students: A phenomenological perspective. Journal of International Students, 10(3), 590-612. https://doi.org/10.32674/ jis.v10i3.1171

Stein, S., \& de Andreotti, V. O. (2016). Cash, competition, or charity: International students and the global imaginary. Higher Education, 72, 225-239. https://doi.org/10.1007/s10734-015-9949-8

Stevens, L. P. (2012). Immigrant populations: Teacher preparation for diversity. In J. A. Banks (Ed.), Encyclopedia of diversity in education (pp. 1132-1135). Sage Publications.

Tikhonova, E. V., Efremova, G. I., \& Kosycheva, M. A. (2021b). Computer simulation as a tool of psychological readiness for the employment process for migrant students. In 2021 th International Conference on Education and Multimedia Technology (ICEMT 2021) (pp. 95-105). Association for Computing Machinery. https://doi. org/10.1145/3481056.3481112

Tikhonova, E., Efremova, G. \& Kosycheva, M. (2021a). A virtual model of migrant students' social and living skills development in the conditions of the host university: Need analysis of migrant students. In The Proceedings of the 2021 IEEE International Conference on Educational Technology (pp. 154-161). ACM. https:// doi.org/10.1109/ICET52293.2021.9563102.

Tomassini, L., Font, X., \& Thomas, R. (2021). The case for linguistic narrative analysis, illustrated by studying small firms in tourism. Tourism Geographies, 23(1-2), 344-359. https://doi.org/10.1080/14616688.2019.161 9824

Ünal, S. (2017). The new actors of international migration: A comparative analysis of foreign students' experiences in a medium-sized city in Turkey. In I. Muenstermann (Ed.), People's movements in the 21st century - Risks, challenges and benefits (pp. 231-257). IntechOpen. https://doi.org/10.5772/67004.

van Krieken, K. (2018). Ambiguous perspective in narrative discourse: Effects of viewpoint markers and verb tense on readers' interpretation of represented perceptions. Discourse Processes, 55(8), 771-786. https://doi. org/10.1080/0163853X.2017.1381540 
Webster, L., \& Mertova, P. (2007). Using narrative inquiry as a research method. Routledge. https://doi. org/10.4324/9780203946268

Wierzbicka, A. (1999). Emotions across languages and Cultures: Diversity and universality. Cambridge University Press.

Xiong, W., Mok, K. H., Ke, G., \& Cheung, J. O. W. (2020). Impact of COVID-19 pandemic on international higher education and student mobility: Student perspectives from Mainland, China and Hong Kong (Working Paper, No. 54). The Centre for Global Higher Education.

Yıldırım, S., Bostancı, S. H., Yıldırım, D. Ç., \& Erdoğan, F.. (2021). Rethinking mobility of international university students during COVID-19 pandemic. Higher Education Evaluation and Development, 15(2), 98-113. https:// doi.org/10.1108/heed-01-2021-0014

Yıldırım, S., Bostancı, S. H., Yıldırım, D. Ç., \& Erdoğan, F. (2021). Rethinking mobility of international university students during COVID-19 pandemic. Higher Education Evaluation and Development, 15, 98-113. https://doi. org/10.1108/heed-01-2021-0014 